\title{
Frequency of Coinfection on the Vaginal Wet Preparation in the Emergency Department
}

\author{
Justin M. Elkins ${ }^{1}$, Santiago Cantillo-Campos ${ }^{1}$, Johnathan M. Sheele ${ }^{1}$
}

1. Emergency Medicine, Mayo Clinic, Jacksonville, USA

Corresponding author: Johnathan M. Sheele, sheele.johnathan@mayo.edu

\section{Abstract \\ Introduction}

Vaginal infections are common in the emergency department (ED) but the frequency of vaginal coinfections identified on wet preparation is unknown.

\section{Methods}

The study examined a data set of 75,000 ED patient encounters between April 18, 2014, and March 7, 2017, who had received testing for gonorrhea, chlamydia, or trichomonas or had received a urinalysis and urine culture during the ED encounter. From this data set we reviewed 16,484 patient encounters where a vaginal wet preparation was performed on women age 18 years and older. Findings from the vaginal wet preparation and ED discharge diagnoses were examined to evaluate the frequency of vaginal coinfections with vulvovaginal candidiasis, trichomoniasis, and bacterial vaginosis.

\section{Results}

Among the women who had wet preparations, 4,124 patient encounters (25.0\%) had a diagnosis of bacterial vaginosis, 625 (3.8\%) had a diagnosis of vulvovaginal candidiasis, and 1,802 (10.9\%) were infected with Trichomonas vaginalis. Twenty encounters $(0.1 \%)$ had a diagnosis of vulvovaginal candidiasis and trichomoniasis; 150 (0.9\%), bacterial vaginosis and trichomoniasis; 136 (0.8\%), vulvovaginal candidiasis and bacterial vaginosis; and $10(0.1 \%)$, trichomoniasis, bacterial vaginosis, and vulvovaginal candidiasis. On vaginal wet preparation, the mean white blood cell count was 13.0 per high-power field. Clue cells were found in 6,988 wet preparations (42.4\%); 1,065 wet preparations (6.5\%) had yeast and 1,377 (8.4\%) had $T$. vaginalis. T. vaginalis was identified in $2.5 \%(266 / 10,542)$ of urinalyses and $8.4 \%(406 / 4,821)$ of nucleic acid amplification tests.

\section{Conclusions}

Vaginal coinfections were uncommon among women receiving a vaginal wet preparation in the emergency department. The most common vaginal coinfection was bacterial vaginosis and trichomonas.

Review began 11/02/2020 Review ended 11/06/2020 Published 11/19/2020

๑) Copyright 2020 Elkins et al. This is an open access article distributed under the terms of the Creative Commons Attribution License CC-BY 4.0., which permits unrestricted use, distribution, and reproduction in any medium, provided the original author and source are credited.
Categories: Emergency Medicine, Obstetrics/Gynecology, Infectious Disease

Keywords: bacterial vaginosis, candidiasis, coinfection, emergency department, trichomonas, vaginitis, emergency medicine, vaginal discharge, wet prep, vaginal wet preparation

\section{Introduction}

Genitourinary concerns are common in the emergency department (ED), where high rates of sexually transmitted infections (STIs) are diagnosed [1]. Although pelvic examinations are routinely performed for women in the ED with genital concerns, the examination itself has questionable utility in helping to diagnose STIs [2-4]. However, pelvic examination and vaginal wet preparation (hereafter called wet prep) can be helpful for establishing a cause for vulvovaginal symptoms, which is an irritation or inflammatory condition of the vagina that can present with an associated odor, itching, and swelling $[5,6]$. Bacterial vaginosis (BV), vulvovaginal candidiasis, and Trichomonas vaginalis infection, in order of decreasing frequency, account for about $70 \%$ to $90 \%$ of vaginitis causes [5-8]. Other causes include desquamative inflammatory vaginitis, aerobic vaginitis, vaginal erosive disease, and atrophic vaginitis $[5,6,9]$. In outpatient clinics, BV is the most common cause of vaginitis, followed by vulvovaginal candidiasis and trichomonas; however, disease prevalence is likely different for an ED population [10,11].

Most wet preps in the ED are performed in women of reproductive age whose vaginal potential of hydrogen $(\mathrm{pH})$ typically ranges from about 4.0 to $5.0[6,12]$. The normal acidic vaginal environment helps inhibit the growth of some pathogenic organisms [12]. A disruption in the normal vaginal microbiome can result in vaginitis from STIs, antibiotic therapy, contraception, douching, foreign bodies [12,13]. Vaginal $\mathrm{pH}$ greater than 4.5 can occur with BV or trichomoniasis; a pH of 4.0 to 4.5 can be seen with vulvovaginal candidiasis [12]. 
Vaginal coinfections have been reported in $5 \%$ to $30 \%$ of women in outpatient gynecology and STI clinics, but none of these studies examined an ED population [14-17]. The coinfection rates for BV and T. vaginalis have been reported to be up to $70 \%$; for BV and vulvovaginal candidiasis, about 25\% [14]. The objective of the present study was to determine the frequency of vaginal coinfections among women undergoing vaginal wet prep in the ED.

\section{Materials And Methods}

Institutional review board approval was obtained from University Hospitals (UH) and Mayo Clinic, and a waiver of informed consent was obtained. We examined a data set of 75,000 UH ED patient encounters that involved testing for gonorrhea, chlamydia, or trichomonas or who had a urinalysis and urine culture obtained in the ED. Data has been previously published from the data set used in this analysis [18]. The data set contained data obtained from the UH electronic health records by a non-clinician who was blinded to the specific study objectives. All patients in the data set were age 18 years or older, and had an ED visit between April 18, 2014, and March 7, 2017. We examined only the data of female patients who had an ED vaginal wet prep result. The vaginal wet preparation white blood cells (WBCs) were reported as ranges 0-5, 5-10, 11-15, 15-25, 25-50, and 50-100 cells per high-power field (HPF), and the means of these ranges were used in the analysis: $2.5,7.5,13,20,37.5$, and 75 respectively so that the data could be modeled as a continuous variable. Vaginal $\mathrm{pH}$ and potassium hydroxide $(\mathrm{KOH})$ tests were not performed on ED vaginal wet prep samples, so the ED diagnosis of BV was clinical, based on history and physical examination findings and laboratory data rather than incorporating all of Amsel's criteria. Women were considered to have a vaginal coinfection if they met two or more of the following conditions: diagnosis of vulvovaginal candidiasis, diagnosis of BV, or positivity for T. vaginalis.

Patients were considered infected with chlamydia or gonorrhea on the basis of the results of a nucleic acid amplification test (NAAT). Patients were deemed infected with trichomonas if they tested positive on a NAAT or if the parasite was identified on urinalysis or a wet prep. Patients were only considered to be negative for T. vaginalis if they had negative NAAT results. Patients with certain International Classification of Diseases, Ninth Revision, and International Classification of Diseases, Tenth Revision, codes for the ED were considered to have BV (codes N76.0, O86.13, 616.10, or 646.6) and vulvovaginal candidiasis (codes B37.3, B37.4, B37.42, B37.49, 112.1, or 112.2). Patients were considered treated for Neisseria gonorrhoeae and Chlamydia trachomatis if they received ceftriaxone or cefixime plus azithromycin in the ED, or received doxycycline as a prescription. Patients with missing or erroneous data were not included in the analysis.

\section{Statistical analysis}

Categorical variables were summarized with frequency and percentage and analyzed with chi-square test. Continuous variables were summarized with mean (SD) and analyzed with Wilcoxon rank-sum test. Odds ratios (ORs) for continuous variables were calculated as the per-unit change in the regressor. Regression analysis was performed with adjustment for age and race. Analyses were performed with statistical software (JMP Pro 14; SAS Corp., Cary, NC, USA). All tests were two-sided, and statistical significance was set at $\mathrm{P} \leqslant .05$. We followed the STROBE (Strengthening the Reporting of Observational Studies in Epidemiology) reporting guidelines for this study.

\section{Results}

\section{Demographic characteristics}

There were 17,184 patient encounters where a woman received a vaginal wet prep in the ED. Among these, the results of 16,484 women with complete vaginal wet prep data were analyzed (Table 1). Mean (SD) age was 28.7 (9.3) years. Most patients were Black/African American and single. Most patients did not have a primary care doctor, had a body mass index of 25 or higher, and were discharged from the ED. The patients had a mean (SD) emergency severity index (ESI) level of $3.2(0.5)$ and a mean (SD) triage pain scale of 5.2 (3.7) (range, 0-10). Most patients were tested for C. trachomatis or N. gonorrhoeae with a NAAT, and 9.6\% were positive for either or both infections. Overall, 1,802 patient encounters in the data set (10.9\%) tested positive for T. vaginalis. This protozoan parasite was identified in $2.5 \%(266 / 10,542)$ of urinalyses, $8.4 \%$ $(1,377 / 16,484)$ of vaginal wet preps, and $8.4 \%(406 / 4,821)$ of NAATs with some women having $T$. vaginalis being diagnosed on multiple tests. Only $29.2 \%(n=4,821)$ of women underwent NAAT testing for T. vaginalis. There were $71.0 \%(4,415 / 6,217)$ of women that were negative for $T$. vaginalis by NAAT. 


\section{Cureus}

\section{Characteristic}

Age, mean (SD), y

Race

Black/African American

White

Asian

Other

Marital status

Single

Married

Divorced

Separated

Life partner

Widowed

Unknown

Discharge from ED (vs admitted)

Primary care doctor (vs not)

ESI mean (SD) (range, 1-5)

$\mathrm{BMI}<25$ (vs $\geq 25$ )

Pain scale, mean (SD) (range, 0-10)

Pregnancy (vs not)

Diagnosis of bacterial vaginosis

Diagnosis of candidiasis

Diagnosis of trichomoniasis

Underwent NAAT for T vaginalis

Positive for T vaginalis ${ }^{\mathrm{b}}$

Underwent NAAT for N gonorrhoeae or C trachomatis, or both

Positive NAAT for $\mathrm{N}$ gonorrhoeae or $\mathrm{C}$ trachomatis, or both
Value $^{\mathrm{a}}(\mathrm{N}=16,484)$

$28.7(9.3)$

$88.7(14,557 / 16,414)$

$9.9(1,629 / 16,414)$

$0.3(53 / 16,414)$

$1.1(175 / 16,414)$

$86.2(14,214 / 16,482)$

$9.3(1,531 / 16,482)$

$2.8(457 / 16,482)$

$0.9(140 / 16,482)$

$0.1(8 / 16,482)$

$0.5(89 / 16,482)$

$0.3(43 / 16,482)$

$94.2(15,524 / 16,484)$

$17.5(2,883 / 16,484)$

$3.2(0.5)(n=15,747)$

$32.9(367 / 1,114)$

$5.2(3.7)(n=1,757)$

$21.9(3,610 / 16,484)$

$25.0(4,124 / 16,484)$

$3.8(625 / 16,484)$

$4.5(732 / 16,484)$

$29.2(4,821 / 16,484)$

$29.0(1,802 / 6,217)$

$97.2(16,021 / 16,484)$

$9.6(1,583 / 16,484)$

\section{TABLE 1: Baseline Characteristics of Patients Undergoing Vaginal Wet Preparation in the ED}

Abbreviations: BMI, body mass index; C. trachomatis, Chlamydia trachomatis, ED, emergency department; ESI, emergency severity index; N, number; NAAT, nucleic acid amplification test; $N$. gonorrhoeae, Neisseria gonorrhoeae; SD, standard deviation; T. vaginalis, Trichomonas vaginalis, vs, versus; $y$, year.

a Values are presented as percentage (number) of patients unless specified otherwise.

b Considered positive for $T$. vaginalis infection if seen on urinalysis or wet preparation or with positive NAAT. Considered negative for $T$. vaginalis only if negative on NAAT. Those who were negative for $T$. vaginalis on wet preparation but did not have NAAT were not included in the denominator. 


\section{Cureus}

vaginal coinfection $(1.9 \%, \mathrm{n}=270)$ compared with women who were not Black/African American $(0.8 \%, \mathrm{n}=14)$ $(\mathrm{P}<.001)$.

No statistically significant difference was observed in the ages between those diagnosed with BV (mean [SD], 28.8 [9.01] years) and those with no BV diagnosis (mean [SD], 28.7 [9.42] years) $(\mathrm{P}=.19)$. The same outcome was observed for patients with and without vulvovaginal candidiasis (mean [SD], 28.9 [10.5] years vs mean, 28.7 [9.28] years) $(\mathrm{P}=.29)$. The women diagnosed with trichomonas infection in the ED were older (mean [SD], 30.3 [9.79] years) than those without it (mean [SD], 28.6 [9.30] years) $(\mathrm{P}<.001)$. Women with vaginal coinfections were older (mean, 30.3 years [SD, 10.17]) than those without coinfection (mean, 28.7 years [SD, 9.31]) $(\mathrm{P}=.006)$.

\section{Vaginal wet prep results on microscopy}

The results of the vaginal wet prep findings are summarized in Table 2. The mean (SD) number of vaginal WBCs was 13.0/HPF (17.6/HPF). The following were present on vaginal wet prep: T. vaginalis, $8.4 \%$ ( $\mathrm{n}=1,377)$; clue cells, $42.4 \%(\mathrm{n}=6,988)$; yeast, $6.5 \%(\mathrm{n}=1,065)$; clue cells and yeast, $2.3 \%(\mathrm{n}=383)$; clue cells and $T$. vaginalis, 3.3\% ( $\mathrm{n}=547)$; and yeast and $T$. vaginalis, $0.4 \%(\mathrm{n}=61)$. Clue cells, T. vaginalis, and yeast were all present from the same patient in only $0.2 \%(n=27)$ of all vaginal wet preps.

\begin{tabular}{|l|l}
\hline Result & Value $^{\mathrm{a}}(\mathrm{N}=16, \mathrm{~s}$ \\
\hline WBC/HPF, mean (SD), No & $13.0(17.6)$ \\
\hline + Clue cells & $6,988(42.4)$ \\
+ Yeast & $1,065(6.5)$ \\
\hline + Trichomonas vaginalis & $1,377(8.4)$ \\
+ Clue cells and + yeast & $383(2.3)$ \\
+ Clue cells and + T vaginalis & $547(3.3)$ \\
+ Yeast and T vaginalis & $61(0.4)$ \\
\hline + Clue cells and + T vaginalis and + yeast & $27(0.2)$
\end{tabular}

\section{TABLE 2: Vaginal Wet Preparation Findings on Microscopy}

Abbreviations: HPF, high-power field; N, number; SD, standard deviation; T. vaginalis, Trichomonas vaginalis, WBC, white blood cell.

a Values are presented as number (\%) of vaginal wet preparations unless specified otherwise.

\section{Association between vaginal wet prep results and ED diagnoses}

Patients were diagnosed with the following: BV, 25.0\% ( $n=4,124)$; vulvovaginal candidiasis, 3.8\% $(n=625)$; trichomoniasis, $4.5 \%(\mathrm{n}=732)$; BV and vulvovaginal candidiasis, $0.8 \%(\mathrm{n}=136)$; vulvovaginal candidiasis and trichomoniasis, $0.1 \%(\mathrm{n}=20)$; BV and trichomoniasis, $0.9 \%(\mathrm{n}=150)$; and trichomoniasis, $\mathrm{BV}$, and vulvovaginal candidiasis, $0.1 \%(\mathrm{n}=10)$ (Table 3). Overall, $1.9 \%(316 / 16,484)$ of women undergoing vaginal wet prep were diagnosed with a vaginal coinfection. 


\section{Cureus}

\begin{tabular}{|c|c|c|c|c|c|c|}
\hline \multirow[b]{2}{*}{ Diagnosis } & \multicolumn{6}{|c|}{ Vaginal wet preparation result ${ }^{\mathrm{a}}(\mathrm{N}=16,484)$} \\
\hline & $\begin{array}{l}\text { WBCs, mean } \\
\text { (SD) }\end{array}$ & $\begin{array}{l}\text { Clue } \\
\text { cells }\end{array}$ & Yeast & $\begin{array}{l}\mathrm{T} \\
\text { vaginalis }\end{array}$ & $\begin{array}{l}+\mathrm{T} \\
\text { vaginalis }^{\mathrm{b}}\end{array}$ & $\begin{array}{l}\text { Overall } \\
\%\end{array}$ \\
\hline Vulvovaginal candidiasis $(\mathrm{N}=625)$ & $17.8(21.3)$ & $\begin{array}{l}178 \\
(28.5)\end{array}$ & $\begin{array}{l}455 \\
(72.8)\end{array}$ & $23(3.7)$ & $36(5.8)$ & 3.8 \\
\hline Bacterial vaginosis $(\mathrm{N}=4,124)$ & $15.4(17.0)$ & $\begin{array}{l}3,663 \\
(88.8)\end{array}$ & $\begin{array}{l}232 \\
(5.6)\end{array}$ & $222(5.4)$ & $298(7.2)$ & 25.0 \\
\hline T vaginalis infection $(\mathrm{N}=737)$ & $21.7(23.7)$ & $\begin{array}{l}286 \\
(39.1)\end{array}$ & $39(5.3)$ & $\begin{array}{l}689 \\
(94.1)\end{array}$ & $713(99.6)$ & 4.5 \\
\hline Vulvovaginal candidiasis and bacterial vaginosis ( $N=136)$ & $17.5(20.3)$ & $\begin{array}{l}121 \\
(89.0)\end{array}$ & $\begin{array}{l}104 \\
(76.5)\end{array}$ & $11(8.1)$ & $15(11.0)$ & 0.8 \\
\hline Vulvovaginal candidiasis and $T$ vaginalis infection $(\mathrm{N}=20)$ & $18.6(17.6)$ & $11(55.0)$ & $20(100)$ & $17(85)$ & $18(100)$ & 0.1 \\
\hline Bacterial vaginosis and T vaginalis infection $(\mathrm{N}=150)$ & $19.7(22.1)$ & $\begin{array}{l}144 \\
(96.0)\end{array}$ & $14(9.3)$ & $\begin{array}{l}141 \\
(94.0)\end{array}$ & $146(99.3)$ & 0.9 \\
\hline $\begin{array}{l}\text { Vulvovaginal candidiasis, bacterial vaginosis, and } \mathrm{T} \text { vaginalis } \\
\text { infection }(\mathrm{N}=10)\end{array}$ & $14.9(12.2)$ & $\begin{array}{l}10 \\
(100.0)\end{array}$ & $\begin{array}{l}10 \\
(100.0)\end{array}$ & $9(90.0)$ & $10(100.0)$ & 0.1 \\
\hline
\end{tabular}

\section{TABLE 3: Diagnoses and the Associated Vaginal Wet Preparation Results}

Abbreviation: N, number; SD, standard deviation; T. vaginalis, Trichomonas vaginalis, WBC, white blood cell.

a Values are presented as number (\%) of patients unless specified otherwise.

b Considered positive for T. vaginalis when seen on urinalysis or wet preparation or with a positive NAAT. Considered negative for T. vaginalis only when a negative NAAT. Those who tested negative for T. vaginalis with wet preparation but who did not have NAAT were not included in the

denominator.

\section{Vaginal WBCs}

Mean vaginal WBC counts were higher for patients whose vaginal wet prep showed clue cells, yeast, and $T$. vaginalis ( $\mathrm{P} \leqslant .001$ for all) (Table 4). Additionally, mean vaginal WBC counts on wet prep were higher for those with vaginal coinfections than those without a coinfection $(\mathrm{P} \leqslant .001)$. 


\section{Cureus}

Result on vaginal wet preparation

Clue cells (+)

Clue cells (-)

Yeast (+)

Yeast (-)

T vaginalis (+)

T vaginalis (-)

Clue cells and yeast (+)

Clue cells and yeast (-)

Clue cells and T vaginalis (+)

Clue cells and $\mathrm{T}$ vaginalis $(-)$

Yeast and T vaginalis (+)

Yeast and T vaginalis (-)

Clue cells, yeast, and T vaginalis (+)

Clue cells, yeast, and T vaginalis (-)
Vaginal WBC/HPF, mean (SD), N.; N. of wet preparations

13.3 (17.1); 6,988

12.7 (18.0); 9,496

19.8 (21.8); 1,065

12.5 (12.5); 15,419

21.6 (23.2); 1,377

12.2 (16.8); 15,107

17.4 (18.9); 383

12.8 (17.6): 16,101

20.2 (22.1); 547

12.7 (17.4); 15,937

20.6 (22.3); 581

12.7 (17.4); 15,903

26.9 (26.4); 27

12.9 (17.6); 16,457

\section{TABLE 4: Vaginal WBCs on Wet Preparation}

Abbreviation: HPF, high-power field; N, number; SD, standard deviation; T. vaginalis, Trichomonas vaginalis, WBC, white blood cell.

\section{Vaginal coinfection compared with no coinfection}

Older age, Black/African American race, discharge from the ED, having a primary care doctor, a higher ESI score, higher vaginal WBC count, higher urine WBC count, more urine bacteria, and higher leukocyte esterase level were associated with higher odds of having a vaginal coinfection on both univariable and regression analyses compared with those with no coinfection ( $\mathrm{P} \leqslant .04$ for all) (Table 5). On both univariable and regression analysis patients with a vaginal coinfection were not more likely to be infected with $C$. trachomatis and/or $N$. gonorrhoeae or have $\geqslant 10$ urine red blood cells on urinalysis. More women with a vaginal coinfection were treated for gonorrhea and chlamydia in the $\mathrm{ED}(\mathrm{P}<.001)$.

\begin{tabular}{|c|c|c|c|c|c|c|}
\hline Characteristic & $\begin{array}{l}\text { + Vaginal } \\
\text { coinfection }^{a}\end{array}$ & $\begin{array}{l}\text { - Vaginal } \\
\text { coinfection }^{a}\end{array}$ & OR $(95 \% \mathrm{Cl})$ & $\begin{array}{l}P \\
\text { value }\end{array}$ & $\begin{array}{l}\text { Adjusted OR } \\
(95 \% \mathrm{CI})\end{array}$ & $\begin{array}{l}\text { Adjusted } P \\
\text { value }\end{array}$ \\
\hline Age, y & 30.3 (10.2); 286 & $\begin{array}{l}28.7(9.3) \\
16,198\end{array}$ & NA & .008 & $1.02(1.01-1.03)$ & .001 \\
\hline Black/African American race (vs not) & $95.1(270 / 284)$ & $\begin{array}{l}88.6 \\
(14,287 / 16,130)\end{array}$ & $\begin{array}{l}2.49(1.45- \\
4.27)\end{array}$ & $\begin{array}{l}< \\
.001\end{array}$ & $2.57(1.50-4.40)$ & $<.001$ \\
\hline Married/life partner (vs other) & $8.0(23 / 286)$ & $\begin{array}{l}9.4 \\
(1,516 / 16,153)\end{array}$ & $\begin{array}{l}0.84(0.55- \\
1.30)\end{array}$ & .54 & $0.87(0.56-1.35)$ & .53 \\
\hline Admitted from ED (vs admit) & $2.8 \%(8 / 286)$ & $\begin{array}{l}5.9 \% \\
(952 / 16,198)\end{array}$ & $.46(.23-.93)$ & .03 & $.47(.23-.96)$ & .04 \\
\hline Primary care doctor (vs not) & $25.2(72 / 286)$ & $\begin{array}{l}17.4 \\
(2,811 / 16,198)\end{array}$ & $\begin{array}{l}1.60(1.22- \\
2.10)\end{array}$ & $\begin{array}{l}< \\
.001\end{array}$ & $1.61(1.23-2.13)$ & $<.001$ \\
\hline ESI (range, 1-5) & $3.3(0.5) ; 261$ & $3.2(0.5) ; 15,486$ & NA & $\begin{array}{l}< \\
.001\end{array}$ & $1.63(1.29-2.07)$ & $<.001$ \\
\hline Triage pain scale (range, $0-10$ ) & $5.2(4.0) ; 33$ & $5.2(3.7) ; 1,724$ & NA & .97 & $1.00(0.91-1.10)$ & .93 \\
\hline Wet preparation WBC, cells/HPF & 18.9 (21.5); 286 & $\begin{array}{l}12.8(17.5) ; \\
16,198\end{array}$ & NA & $\begin{array}{l}< \\
.001\end{array}$ & $1.01(1.01-1.02)$ & $<.001$ \\
\hline
\end{tabular}




\section{Cureus}

\begin{tabular}{|c|c|c|c|c|c|c|}
\hline Wet preparation +clue cells & $89.5(256 / 286)$ & $\begin{array}{l}41.6 \\
(6,732 / 16,198)\end{array}$ & $\begin{array}{l}12.0(8.21 \text { - } \\
17.54)\end{array}$ & $\begin{array}{l}< \\
.001\end{array}$ & $\begin{array}{l}11.86(8.10- \\
17.37)\end{array}$ & $<.001$ \\
\hline Wet preparation +yeast & $41.3(118 / 286)$ & $5.9(947 / 16,198)$ & $\begin{array}{l}11.31(8.86- \\
14.44)\end{array}$ & $\begin{array}{l}< \\
.001\end{array}$ & $\begin{array}{l}11.44(8.94- \\
14.63)\end{array}$ & $<.001$ \\
\hline Wet preparation $+\mathrm{T}$ vaginalis & $52.8(151 / 286)$ & $\begin{array}{l}7.6 \\
(1,226 / 16,198)\end{array}$ & $\begin{array}{l}13.66(10.75- \\
17.35)\end{array}$ & $\begin{array}{l}< \\
.001\end{array}$ & $\begin{array}{l}12.87(10.10- \\
16.38)\end{array}$ & $<.001$ \\
\hline Positive for $T$ vaginalis $^{b}$ & $87.5(161 / 184)$ & $\begin{array}{l}27.2 \\
(1,641 / 6,033)\end{array}$ & $\begin{array}{l}18.7(12.1- \\
29.1)\end{array}$ & $\begin{array}{l}< \\
.001\end{array}$ & $\begin{array}{l}17.96(11.53- \\
27.98)\end{array}$ & $<.001$ \\
\hline $\begin{array}{l}\text { Infection with Neisseria gonorrhoeae, Chlamydia } \\
\text { trachomatis, or both }\end{array}$ & $11.7(33 / 281)$ & $\begin{array}{l}9.9 \\
(1,556 / 15,782)\end{array}$ & $\begin{array}{l}1.22(0.84- \\
1.76)\end{array}$ & .31 & $1.30(0.89-1.91)$ & .17 \\
\hline Urine WBCs, $\geq 10$ cells/HPF & 142 (61.7); 230 & $\begin{array}{l}4197(40.6) ; \\
10,346\end{array}$ & NA & $\begin{array}{l}< \\
.001\end{array}$ & $2.37(1.81-3.11)$ & $<.001$ \\
\hline Urine RBCs, $\geq 10$ cells/HPF & 65 (28.4); 229 & $\begin{array}{l}3064(29.6) ; \\
10,344\end{array}$ & $\mathrm{NA}$ & .71 & $0.95(0.71-1.27)$ & .71 \\
\hline Urine bacteria $(0,1+, 2+, 3+, 4+)$ & $1.2(1.2) ; 231$ & 1.0 (1.1); 10,345 & NA & .001 & $1.19(1.06-1.33)$ & .002 \\
\hline Urine leukocyte esterase $(0,1+, 2+, 3+$, or $4+)$ & $1.8(1.3) ; 260$ & $0.8(1.1) ; 14,339$ & NA & $\begin{array}{l}< \\
.001\end{array}$ & $1.88(1.70-2.07)$ & $<.001$ \\
\hline Positive urine nitrite (vs negative) & $4.9(13 / 263)$ & $3.7(531 / 14,370)$ & $1.4(0.8-2.4)$ & .32 & $1.35(0.76-2.37)$ & .30 \\
\hline Urine $\mathrm{pH}$ (range, 5-9) & $6.0(0.9) ; 263$ & $6.0(0.9) ; 14,374$ & NA & .97 & $1.02(0.89-1.17)$ & .74 \\
\hline Metronidazole given in ED or prescription (vs not) & $87.4(250 / 286)$ & $\begin{array}{l}39.6 \\
(6,412 / 16,198)\end{array}$ & $\begin{array}{l}10.6(7.5- \\
15.1)\end{array}$ & $\begin{array}{l}< \\
.001\end{array}$ & $\begin{array}{l}10.56(7.39- \\
15.09)\end{array}$ & $<.001$ \\
\hline Treated for gonorrhea/chlamydia in ED (vs I & $35.0(100 / 286)$ & $\begin{array}{l}18.2 \\
(2,954 / 16,198)\end{array}$ & $.4(1.9-3$. & $\begin{array}{l}< \\
.001\end{array}$ & $2.37(1.85-3.04)$ & $<.001$ \\
\hline
\end{tabular}

\section{TABLE 5: Associations With a Diagnosis of Vaginal Coinfection}

Abbreviations: Cl, confidence interval; ED, emergency department; ESI, emergency severity index; HPF, high-power field; OR, odds ratio; RBC, red blood cell; T. vaginalis, Trichomonas vaginalis; vs, versus; WBC, white blood cell; y, year.

a Presented as percentage and number of patients or mean (SD) and number of patients.

b Considered positive for $T$. vaginalis if seen on urinalysis or wet preparation, or had a positive NAAT. Considered negative for $T$. vaginalis only if negative by NAAT. Those who were negative for T. vaginalis by wet preparation but who did not have a NAAT were not included in the denominator.

\section{Discussion}

Vaginal coinfections of candidiasis, trichomonas, and BV are uncommon and only occurred in $1.9 \%$ $(316 / 16,484)$ of women undergoing vaginal wet prep in the ED. The most common causes of vaginal coinfections were BV and trichomoniasis, vulvovaginal candidiasis and trichomoniasis, and vulvovaginal candidiasis and BV. Cases of vulvovaginal candidiasis, trichomoniasis, and BV were rare. Vaginal coinfections were significantly associated with older age, Black/African American race, having a primary care doctor, having a higher ESI level, treatment of gonorrhea and chlamydia, discharge from the ED, a greater vaginal WBC count, and on urinalysis having greater values of WBCs, bacteria, and leukocyte esterase. Some findings were in concordance with what has been published previously, such as trichomonas occurrence in older women; that Black/African American women were more likely to be diagnosed with BV, vulvovaginal candidiasis, and trichomoniasis; and that BV and trichomonas are the most common causes of vaginal coinfection $[5,14,18-24]$.

The most common cause of vaginitis diagnosed in the ED was BV, followed in order of frequency by $T$. vaginalis and vulvovaginal candidiasis. The prevalence of these diseases in the ED is different than what has been reported in outpatient clinics, where vulvovaginal candidiasis has been reported with greater frequency [7,11]. Additionally, previous studies have shown that both T. vaginalis and BV are associated with N. gonorrhoeae and C. trachomatis infection and that T. vaginalis can be associated with BV [19,25-27]. Our data did not show that vaginal coinfections were associated with $N$. gonorrhoeae or C. trachomatis, or both.

\section{Limitations}


The data set contained patient encounters and some patients presented to the ED multiple times. The ED patients in our data set were likely presenting with genitourinary complaint in order to receive a vaginal wet prep in the ED. The data set lacked racial diversity, and all data came from hospitals in northeast Ohio. Since only ED patient encounters were examined our results are not likely to be generalizable to all women or those being evaluated in outpatient clinics. Only the three most common vaginal infections in the ED were examined in this study; other causes of vaginitis, such as aerobic vaginitis and cytolytic vaginosis, are not typically diagnosed in the ED [5,28]. For some patients for whom coinfections were identified, one pathogen may not have caused any vaginal symptoms. For instance, $20 \%$ of asymptomatic women had culturable yeast from the vagina, and the majority of women with trichomonas infection may be asymptomatic $[5,12]$. Neither vaginal $\mathrm{pH}$ measurements nor the whiff test (ie, potassium hydroxide $(\mathrm{KOH})$ added to the vaginal discharge) was performed in the ED or on ED samples, thus preventing the calculation of Amsel criteria for BV. Yet, the presence of two of the four Amsel criteria (eg, a gray-white thin or watery discharge plus clue cells) may perform as well as three of four criteria for the diagnosis of BV [5,29]. The Nugent score for diagnosing BV is rarely used clinically and was not used in the ED for the BV diagnosis [5]. Neither direct probe assays nor NAATs were used to aid in the BV diagnosis [5]. The use of molecular tests would likely have increased the number of positive single infections and coinfections in our data set [30].

\section{Conclusions}

Vaginal coinfections with T. vaginalis, BV, and candidiasis are infrequent, occurring in only $1.9 \%$ of women undergoing wet prep in the ED. The most common vaginal coinfections were BV and trichomonas, candidiasis and BV, candidiasis and trichomonas, and BV, candidiasis, and trichomonas. Vaginal coinfections were associated with older age, Black/African American race, having a primary care doctor, and not being married or not having a life partner. Women with a vaginal coinfection were not more likely to be infected with $N$. gonorrhoeae or C. trachomatis, or both, but were more likely to be treated for gonorrhea and chlamydia in the ED. Vaginal coinfections were found to be associated with a greater number of vaginal WBCs, urine WBCs, and urine bacteria and with greater urine leukocyte esterase values.

\section{Additional Information}

\section{Disclosures}

Human subjects: Consent was obtained by all participants in this study. University Hospitals issued approval 18-008945. This study was approved by University Hospitals and the Mayo Clinic. Animal subjects: All authors have confirmed that this study did not involve animal subjects or tissue. Conflicts of interest: In compliance with the ICMJE uniform disclosure form, all authors declare the following: Payment/services info: All authors have declared that no financial support was received from any organization for the submitted work. Financial relationships: All authors have declared that they have no financial relationships at present or within the previous three years with any organizations that might have an interest in the submitted work. Other relationships: All authors have declared that there are no other relationships or activities that could appear to have influenced the submitted work.

\section{References}

1. Wilson SP, Vohra T, Knych M, et al.: Gonorrhea and chlamydia in the emergency department: continued need for more focused treatment for men, women and pregnant women. Am J Emerg Med. 2017, 35:701-703. 10.1016/j.ajem.2017.01.002

2. Tucker P, Evans DD: Are pelvic exams necessary anymore?. Adv Emerg Nurs J. 2019, 41:282-289. 10.1097/TME.0000000000000269

3. Brown J, Fleming R, Aristzabel J, Gishta R: Does pelvic exam in the emergency department add useful information?. West J Emerg Med. 2011, 12:208-212.

4. Reed JL, Mahabee-Gittens EM, Huppert JS: A decision rule to identify adolescent females with cervical infections. J Womens Health. 2007, 16:272-80. 10.1089/jwh.2006.M077

5. Neal CM, Kus LH, Eckert LO, Peipert JF: Noncandidal vaginitis: a comprehensive approach to diagnosis and management. Am J Obstet Gynecol. 2020, 222:114-122. 10.1016/j.ajog.2019.09.001

6. Mills BB: Vaginitis: beyond the basics. Obstet Gynecol Clin North Am. 2017, 44:159-177. 10.1016/j.ogc.2017.02.010

7. Sobel JD: Vulvovaginitis in healthy women. Compr Ther. 1999, 25:335-346. 10.1007/BF02944280

8. Paladine HL, Desai UA: Vaginitis: diagnosis and treatment. Am Fam Physician. 2018, 97:321-329.

9. Wang ZL, Fu LY, Xiong ZA, et al.: Diagnosis and microecological characteristics of aerobic vaginitis in outpatients based on preformed enzymes. Taiwan J Obstet Gynecol. 2016, 55:40-44. 10.1016/j.tjog.2015.06.012

10. Mulley AG Jr: Approach to the patient with a vaginal discharge . Primary Care Medicine: Office Evaluation and Management of the Adult Patient. Goroll AH, Mulley AG Jr (ed): Lippincott Williams \& Wilkins, Philadelphia; 2000. 702-7. 10.1001/jama.1995.03520430082051

11. Anderson MR, Klink K, Cohrssen A: Evaluation of vaginal complaints. JAMA. 2004, 291:1368-1379. 10.1001/jama.291.11.1368

12. Kalia N, Singh J, Kaur M: Microbiota in vaginal health and pathogenesis of recurrent vulvovaginal infections: a critical review. Ann Clin Microbiol Antimicrob. 2020, 19:5. 10.1186/s12941-020-0347-4

13. Javed A, Parvaiz F, Manzoor S: Bacterial vaginosis: an insight into the prevalence, alternative treatments regimen and it's associated resistance patterns. Microb Pathog. 2019, 127:21-30.

10.1016/j.micpath.2018.11.046 
14. Sobel JD, Subramanian C, Foxman B, Fairfax M, Gygax SE: Mixed vaginitis-more than coinfection and with therapeutic implications. Curr Infect Dis Rep. 2013, 15:104-108. 10.1007/s11908-013-0325-5

15. Ferris DG, Hendrich J, Payne PM, et al.: Office laboratory diagnosis of vaginitis. Clinician-performed tests compared with a rapid nucleic acid hybridization test. J Fam Pract. 1995, 41:575-581.

16. Mardh PA, Tchoudomirova K, Elshibly S, Hellberg D: Symptoms and signs in single and mixed genital infections. Int J Gynaecol Obstet. 1998, 63:145-152. 10.1016/s0020-7292(98)00140-4

17. Rivers CA, Adaramola OO, Schwebke JR: Prevalence of bacterial vaginosis and vulvovaginal candidiasis mixed infection in a southeastern american STD clinic. Sex Transm Dis. 2011, 38:672-674. 10.1097/OLQ.0b013e31820fc3b8

18. Elkins JM, Hamid OS, Simon LV, Sheele JM: Association of Bartholin cysts and abscesses and sexually transmitted infections. Am J Emerg Med. 2020, 10.1016/j.ajem.2020.04.027

19. Workowski KA, Bolan GA: Sexually transmitted diseases treatment guidelines, 2015. MMWR Recomm Rep. 2015, 64:1-137.

20. Foxman B, Muraglia R, Dietz JP, Sobel JD, Wagner J: Prevalence of recurrent vulvovaginal candidiasis in 5 European countries and the United States: results from an internet panel survey. J Low Genit Tract Dis. 2013, 17:340-345. 10.1097/LGT.0b013e318273e8cf

21. Allsworth JE, Peipert JF: Prevalence of bacterial vaginosis: 2001-2004 National Health and Nutrition Examination Survey data. Obstet Gynecol. 2007, 109:114-120. 10.1097/01.AOG.0000247627.84791.91

22. Gatski M, Martin DH, Clark RA, Harville E, Schmidt N, Kissinger P: Co-occurrence of Trichomonas vaginalis and bacterial vaginosis among HIV-positive women. Sex Transm Dis. 2011, 38:163-166. 10.1097/OLQ.0b013e3181f22f56

23. Moodley P, Connolly C, Sturm AW: Interrelationships among human immunodeficiency virus type 1 infection, bacterial vaginosis, trichomoniasis, and the presence of yeasts. J Infect Dis. 2002, 185:69-73. $10.1086 / 338027$

24. Rathod SD, Krupp K, Klausner JD, Arun A, Reingold AL, Madhivanan P: Bacterial vaginosis and risk for Trichomonas vaginalis infection: a longitudinal analysis. Sex Transm Dis. 2011, 38:882-886. 10.1097/OLQ.0b013e31821f91a1

25. Fastring DR, Amedee A, Gatski M, et al.: Co-occurrence of Trichomonas vaginalis and bacterial vaginosis and vaginal shedding of HIV-1 RNA. Sex Transm Dis. 2014, 41:173-179. 10.1097/OLQ.0000000000000089

26. Jespers V, Crucitti T, Menten J, et al.: Prevalence and correlates of bacterial vaginosis in different subpopulations of women in sub-Saharan Africa: a cross-sectional study. PLoS One. 2014, 9:109670. 10.1371/journal.pone.0109670

27. El Sayed Zaki M, Raafat D, El Emshaty W, Azab MS, Goda H: Correlation of Trichomonas vaginalis to bacterial vaginosis: a laboratory-based study. J Infect Dev Ctries. 2010, 4:156-163. 10.3855/jidc.434

28. Fan A, Yue Y, Geng N, Zhang H, Wang Y, Xue F: Aerobic vaginitis and mixed infections: comparison of clinical and laboratory findings. Arch Gynecol Obstet. 2013, 287:329-335. 10.1007/s00404-012-2571-4

29. Gutman RE, Peipert JF, Weitzen S, Blume J: Evaluation of clinical methods for diagnosing bacterial vaginosis. Obstet Gynecol. 2005, 105:551-556. 10.1097/01.AOG.0000145752.97999.67

30. Schwebke JR, Gaydos CA, Nyirjesy P, Paradis S, Kodsi S, Cooper CK: Diagnostic performance of a molecular test versus clinician assessment of vaginitis. J Clin Microbiol. 2018, 56:e00252-18. 10.1128/JCM.00252-18 